\title{
Preface of the special issue on "A bespoke approach to rectal cancer resection and management"
}

\author{
Gordon N. Buchanan \\ Department of Colorectal Surgeon, Lister Hospital, London SW1W 8RH, UK. \\ Correspondence to: Dr. Gordon N. Buchanan, Department of Colorectal Surgeon, Lister Hospital, Chelsea Bridge Road, \\ London SW1W 8RH, UK. E-mail: gordon.buchanan@hcaconsultant.co.uk
}

How to cite this article: Buchanan GN. Preface of the special issue on "A bespoke approach to rectal cancer resection and management". Mini-invasive Surg 2019;3:8. http://dx.doi.org/10.20517/2574-1225.2019.24

Received: 5 Mar 2019 Accepted: 11 Mar 2019 Published: 28 Mar 2019

Science Editor: Charles F. Bellows Copy Editor: Cai-Hong Wang Production Editor: Huan-Liang Wu

Rectal cancer is increasingly managed by super-specialist colorectal and oncological teams - this has only become possible through the belief and drive of many key figures who often, despite lack of support from their peers, persevered in order to define the aspect of care they truly believed beneficial to improve outcomes. It is this collective work across decades that has enabled patients to have choice in scenarios that were often previously both bleak and debilitating. It is a great honour to act as guest editor for this special edition where many of these key international opinion leaders have generously contributed to help coalesce the goal for a bespoke approach to rectal cancer.

Tebala et $a l .{ }^{[1]}$ discuss the role of enhanced recovery and demonstrate how it can shorten stay and potentially reduce complications in this complex set of patients.

Chouhan et al. ${ }^{[2]}$, with input both from the greatly experienced Korean and Australasian teams, have discussed in great depth the potential benefits of the robotic platform and even in early trials noted the trend to reduced conversion $v s$. laparoscopic resection in the obese male - as numbers grow this almost certainly will become more evident. They liken the robot to an open approach with its wrist movement but providing a more magnified view and the benefits of a minimally invasive surgery (MIS) approach. They provide some evidence that the robotic approach may improve survival potentially combined with better pathological outcomes; these benefits are further reviewed by Chen et al. ${ }^{[3]}$ from Taiwan who found this technique safe in low lying rectal cancer. 
Yellinek and Wexner ${ }^{[4]}$, writing from the Cleveland clinic, discuss an alternative to the robot, namely transanal total mesorectal excision (TaTME), the importance of a registry and training programme though conclude that the single port robot may provide a method for better adopting this technique, potentially as a combined approach and ongoing trial data is awaited. De Nardi ${ }^{[5]}$ suggests that TaTME has comparable functional outcomes compared with the abdominal approach though the COLOR III trial results are eagerly awaited to assess this.

Ishida et al. ${ }^{[6]}$ recognise the difficulty associated with learning reduce port surgery, though again note that this technique once mastered may yield benefits in terms reduced operating time over single incision laparoscopic surgery, particularly with advancements in needlescopic surgery.

Ambe and Möslein ${ }^{[7]}$ discuss the role of extended resections in certain mutational and hereditary analyses, making the point that each case must be considered on its own merits after fully informed discussion with patients about the risks and benefits of each approach - this detailed piece provides an up to date review of most of the important hereditary and mutational conditions, how they are classified and defined as well as many operative illustrations pointing out the various surgical approaches possible.

$\mathrm{Kumar}^{[8]}$ looks beyond TME and the role of MIS surgery in exenterative surgery, pelvic lymphadenectomy and even abdomino-sacral resection.

Funahashi ${ }^{[9]}$ and colleagues outline their experience in Japanese patients of intersphincteric resection in low lying rectal cancer and how it can lead to organ preservation in many without compromising pathological outcomes - they notes the improved quality of life after preserving as much of the internal anal sphincter as possible.

O'Donohue et al. ${ }^{[10]}$ explore whether laparoscopic rectal surgery is non inferior, particularly assessing the COREAN, ALaCaRT and ACOSOG Z6051 trials. The concept of non-inferiority in the short term, vs. equivalent long term outcomes should not cloud the picture of the many advantages of an MIS approach, that are likely to be borne out with larger population based studies.

Westwood and West ${ }^{[11]}$ emphasise how pathologists enhance feedback and thus quality of rectal cancer specimens and thus, patient outcomes. This quality control was largely the work of Quirke, coupled with imaging expertise from Brown $G$ working with resection material generated via Heald in TME surgery - initially surgeons felt affronted by resections being graded though with importance on outcome, now entirely value the essential role of feeding this back via their multidisciplinary teams.

Erkan, Kelly and Monson ${ }^{[12]}$ in Florida review the role of the transanal minimally invasive surgery (TAMIS) platform in locally resecting rectal cancer, particularly in T1 lesions or after chemo-radiotherapy and more controversially T2/4 lesions even in palliative scenarios - again Adegbola et al ${ }^{[13]}$ from St Mark's, UK, additionally discuss the role of TAMIS with a robotic platform in exenterative surgery and other scenarios - i.e., trying to avoid major resectional surgery altogether.

Myint ${ }^{[14]}$ discusses the alternative of brachytherapy to radical resection and that patients with knowledge of this may reject MDT recommendations in favour of a more conservative approach - the OPERA database (organ preservation) will help provide useful outcome information in this regard.

All of these articles are well written and many beautifully illustrated, giving a concise appraisal of state of the art techniques. Some highlighted above do not take away all the other well-constructed opinion pieces that expand on the themes generated through principles of TME surgery and multidisciplinary input into this group of patients. 


\section{DECLARATIONS}

\section{Authors' contributions}

Buchanan GN contributed solely to this preface.

\section{Availability of data and materials}

Not applicable.

\section{Financial support and sponsorship}

None.

\section{Conflicts of interest}

The author declared that there are no conflicts of interest.

\section{Ethical approval and consent to participate}

Not applicable.

\section{Consent for publication}

Not applicable.

\section{Copyright}

(c) The Author(s) 2019.

\section{REFERENCES}

1. Tebala GD, Gordon-Dixon A, Imtiaz M, Shrestha A, Toeima M. Enhanced recovery after rectal surgery: what we have learned so far. Mini-invasive Surg 2018;2:32.

2. Chouhan H, Shin J, Kim SH. Is robotic rectal resection the preferred option for resectable cancer? Mini-invasive Surg 2018;2:18.

3. Chen PJ, Huang CW, Tsai HL, Yeh YS, Su WC, et al. Robotic-assisted total mesorectal excision in low-lying rectal cancer. Miniinvasive Surg 2018;2:43.

4. Yellinek S, Wexner SD. The role of transanal total mesorectal excision in rectal surgery. Mini-invasive Surg 2018;2:22.

5. De Nardi P. Functional results and quality of life after transanal total mesorectal excision. Mini-invasive Surg 2018;2:20.

6. Ishida T, Shigeta K, Okabayashi K, Tsuruta M, Hasegawa H, et al. Reduced-port surgery for rectal cancer. Mini-invasive Surg 2018;2:31.

7. Ambe PC, Möslein G. Surgical management of hereditary colorectal cancer. Mini-invasive Surg 2018;2:37.

8. Kumar NAN, Kammar P, Saklani A. Minimal invasive approach for beyond total mesorectal excision/extended resections in rectal cancer. Mini-invasive Surg 2018;2:19.

9. Funahashi K, Koike J, Shiokawa H, Ushigome M, Kaneko T, et al. Clinical feasibility of sphincter-preserving resection with transanal rectal dissection for low-lying rectal cancer in Japanese patients: a single-center cohort study. Mini-invasive Surg 2018;2:27.

10. O'Donohue PF, Warren CD, Chow CFK. Is laparoscopic rectal surgery really not non-inferior? Mini-invasive Surg 2018;2:24.

11. Westwood AC, West NP. The importance of pathological quality control for rectal surgery. Mini-invasive Surg 2018;2:38.

12. Erkan A, Kelly JJ, Monson JRT. Current state of transanal minimally invasive surgery in the management of rectal cancer. Mini-invasive Surg 2018;2:30.

13. Adegbola SO, Sahnan K, Pellino G, Warusavitarne J. Transanal minimal invasive surgery - pushing the boundaries of transanal surgery. Mini-invasive Surg 2018;2:40.

14. Myint AS, Gerard JP. Minimally invasive contact X-ray brachytherapy as an alternative option in patients with rectal cancer not suitable for bespoke surgical resection. Mini-invasive Surg 2018;2:34. 